\title{
Analisis Dan Perancangan Sistem Informasi 20 Besar Penyakit Rujukan Di UPT Puskesmas Babakan Sari Bandung
}

\author{
Rini Suwartika Kusumadiarti ${ }^{1}$ Santika Suri Nur Indah ${ }^{2}$ \\ Program Studi Manajemen Informatika Diploma IV Konsentrasi Informatika Rekam Medis, \\ rinisuwartika@yahoo.com
}

\begin{abstract}
Health service is an effort that is carried out alone or jointly in an organization to maintain and improve health, prevent, and cure diseases and restore the health of individuals, families, and communities. One of the services performed is by providing medical record services. This study aims to determine how the information system design of the top 20 referral diseases as one of the management of medical record data in UPT Puskesmas Babakan Sari Bandung. The method used is a qualitative research method with a descriptive approach. Data collection techniques used are by observation, interview, and equipped with literature study. The software development method used is the waterfall method. As for the advice that the author gives, namely: Created a system of 20 major diseases that can accelerate the referral of making reports of 20 major diseases, it is necessary to increase the number of health workers in carrying out activities of the top 20 referral diseases, Conduct training to administrative officers or users of the system.
\end{abstract}

Keywords: Information Systems, Referral, Microsoft Visual Studio 2010

\begin{abstract}
Abstrak- Pelayanan kesehatan merupakan upaya yang diselenggarakan sendiri atau secara bersama-sama dalam suatu organisasi untuk memelihara dan meningkatkan kesehatan, mencegah, dan menyembuhkan penyakit serta memulihkan kesehatan perorangan, keluarga, dan masyarakat. Salah satu pelayanan yang dilakukan adalah dengan mengadakan pelayanan rekam medis. Penelitian ini bertujuan untuk mengetahui bagaimana perancangan sistem informasi 20 besar penyakit rujukan sebagai salah satu pengelolaan data rekam medis di UPT Puskesmas Babakan Sari Kota Bandung. Metode yang digunakan adalah metode penelitian kualitatif dengan pendekatan deskriptif. Teknik pengumpulan data yang digunakan adalah dengan cara observasi, wawancara, serta dilengkapi dengan studi pustaka. Metode pengembangan perangkat lunak yang digunakan adalah metode waterfall. Adapun saran yang penulis berikan yaitu: Dibuatkan sistem informasi 20 besar penyakit rujukan yang dapat mempercepat pembuatan laporan 20 besar penyakit rujukan, Perlu adanya penambahan tenaga kesehatan dalam melakukan kegiatan laporan 20 besar penyakit rujukan, Mengadakan pelatihan kepada petugas tata usaha atau pengguna sistem.
\end{abstract}

Kata Kunci: Sistem Informasi, Rujukan

\section{PENDAHULUAN}

\section{Latar Belakang Penelitian}

Perkembangan dan kemajuan ilmu pengetahuan dadiselenggarakan sendiri atau secara bersama-sama teknologi pada saat ini memegang peranan pentindglam suatu organisasi untuk memelihara dan terhadap berbagai aspek kehidupan terutama di bidangeningkatkan kesehatan, mencegah, dan teknologi informasi. Dengan berkembangnya teknologienyembuhkan penyakit serta memulihkan kesehatan informasi maka informasi yang didapat akan lebiperorangan, keluarga, dan masyarakat.Puskesmas mudah dan cepat. Diharapkan pengambilan keputusadalah suatu unit pelaksana fungsional yang berfungsi pun dapat dilakukan dengan tepat dan akurat. Sehinggxabagai pusat pembangunan kesehatan. Pusat dapat mengurangi terjadinya kesalahan yang tidakembinaan peran serta masyarakat dalam bidang diharapkan sehingga dapat meningkatkan kinerja yankesehatan serta pusat pelayanan kesehatan tingkat lebih efisien dan kecepatan operasional instansi.Begipertama yang menyelenggarakan kegiatannnya secara banyak instansi baik swasta maupun pemerintah yangenyeluruh, terpadu yang berkesinambungan pada menggunakan kemajuan teknologi informasi sebagaiatu masyarakat yang bertempat tinggal dalam suatau upaya dalam peningkatan kualitas pelayanan. Salakilayah tertentu (Azrul azwar, 1996).Salah satu upaya satunya adalah puskesmas yang memberikan pelayanameningkatkan mutu pelayanan kesehatan puskesmas kesehatan kepada masyarakat dengan sebaik-baiknyadalah dengan mengadakan pelayanan rekam medis. Pelayanan kesehatan merupakan upaya yangekam medis adalah keterangan baik tertulis maupun 
catatan tentang identitas pasien, anamnesa, penentuamembutuhkan waktu lebih lama, menimbulkan kurang fisik, laboratorium, diagnosa segala pelayanan dakuratnya informasi yang dihasilkan dan keterlambatan tindakan medik yang diberikan kepada pasien rawaerta kesulitan dalam pembuatan laporan. Berdasarkan jalan, rawat inap, maupun pelayanan gawhatar belakang diatas, maka penulis tertarik untuk darurat.Rekam Medis mempunyai tujuan yaimengambil judul "Perancangan Sistem Informasi 20 menunjang tercapainya tertib administrasi dalaßesar Penyakit Rujukan Menggunakan Microsoft rangka upaya peningkatan pelayanan kesehatan. Tanpkisual Studio 2010 Di UPT Puskesmas Babakan didukung suatu sistem pengelolaan rekam medis yanfari Kota Bandung" baik dan benar, tidak akan tercipta tertib administrasi. Salah satu tujuuan dari sistem pengelolaan rekam medis yaitu untuk menghasilkan laporan.Pengelolaan data di Puskesmas merupakan salah satu komponen yang penting dalam mewujudkan suatu sistem informasi di Puskesmas. Dengan dukungan teknologi informasi yang semakin berkembang sekarang ini sebuah instansi kesehatan dapat dengan mudah mengambil keputusan dalam pengolahan data sehingga dapat menghasilkan laporan. Salah satunya laporan jumlah penyakit terbanyak berdasarkan rujukan yang mana dari kegiatan pelaporan tersebut menghasilkan dua laporan yang dibutuhkan baik oleh pihak internal maupun external. Salah satunya pengolahan data yang harus dilaporkan adalah dengan membuat laporan 20 besar penyakit rujukan yang banyak dirujuk di puskesmas. Surat rujukan merupakan pelimpahan tanggung jawab kepada fasilitas kesehatan tingkat lanjut yang memiliki tenaga spesialis yang dapat menangani kasus yang terjadi ditingkat fasilitas kesehatan pertama yang tidak bisa diatasi. Pelaksanaan sistem rujukan di indonesia telah diatur dengan bentuk bertingkat atau berjenjang, yaitu pelayanan kesehatan tingkat pertama, kedua, dan ketiga. Dimana dalam pelaksanaannya tidak berdiri sendiri, namun berada di suatu sistem dan saling berhubungan, apabila pelayanan kesehatan primer tidak dapat melakukan tindakan medis tingkat primer maka ia menyerahkan tanggung jawab tersebut ke tingkat pelayanan diatasnya demikian seterusnya. Berdasarkan hasil Praktek Kerja Lapangan (PKL) penulis di UPT Puskesmas Babakan Sari Kota Bandung, terdapat permasalahan diantaranya rekapitulasi jumlah penyakit untuk laporan 20 besar penyakit yang berdasarkan rujukan masih dilakukan secara manual dengan menghitung satu persatu diagnosa kemudian mengelompokan jumlah penyakit rujukan yang selanjutnya akan ditentukan kode penyakitnya dengan ditulis ulang dalam kertas, yang kemudian dimasukan ke dalam program microsoft excel sehingga

\section{Pokok Permasalahan}

Berdasarkan latar belakang permasalahan pokok permasalahan yang dikemukakan adalah Bagaimana Perancangan Sistem Informasi 20 Besar Penyakit Rujukan Di UPT Puskesmas Babakan Sari Kota Bandung.

\section{Tujuan dan Manfaat Penelitian}

\section{A. Tujuan Penelitian}

1. Tujuan Umum

Untuk mengetahui perancangan sistem informasi 20 besar penyakit rujukan menggunakan microsoft visual studio $2010 \mathrm{di}$ UPT Puskesmas Babakan Sari Kota Bandung.

2. Tujuan Khusus

a. Untuk mengetahui sistem informasi pelaporan 20 besar penyakit rujukan di UPT Puskesmas Babakan sari.

b. Untuk mengetahui permasalahan apa saja yang terdapat dalam sistem informasi 20 besar penyakit rujukan di UPT Puskesmas Babakan Sari.

c. Untuk mengetahui upayaupaya apa yang dilakukan untuk mengatasi permasalahan yang terdapat dalam pelaporan sistem informasi 20 besar penyakit rujukan.

\section{B. Manfaat Penelitian}

1. Bagi Penulis
a. Mendapatkan
wawasan, pengalaman, 
melalui kegiatan-kegiatan yang dilakukan di lapangan khususnya mengenai sistem informasi 20 besar penyakit rujukan beserta permasalahan yang mungkin timbul dan upaya penyelesaiannya.

2. Bagi Puskesmas

Hasil penelitian ini diharapkan dapat bermanfaat bagi Puskesmas Babakan Sari kota Bandung sebagai bahan pertimbangan untuk meningkatkan sistem informasi khususnya di sistem informasi 20 besar penyakit rujukan sehingga dapat menyajikan informasi secara cepat dan akurat.

3. Bagi Institusi Pendidikan/Bagi Akademik

a. Hasil penelitian ini diharapkan dapat bermanfaat sebagai referensi pembelajaran bagi seluruh mahasiswa khususnya di bidang rekam medis.

b. Hasil penelitian dapat digunakan sebagai bahan penelitian lanjutan.

\section{KAJIAN TEORITIS}

\section{A. Pengertian Puskesmas}

Menurut Keputusan Menteri Kesehatan Republik Indonesia No. 128/MENKES/SK/II/2004: "Puskesmas adalah unit pelaksanaan teknis dinas kesehatan kabupaten atau kota yang bertanggung jawab menyelenggarakan pembangunan kesehatan di suatu wilayah kerja".

\section{B. Pengertian Rekam Medis}

Menurut Peraturan Menteri Kesehatan Republik Indonesia No.269/MENKES/per/III/2008: "Rekam Medis adalah Berkas yang berisikan catatan dan dokmen tentang identias pasien, pemeriksaan, pengobatan, tindakan, dan pelayanan lain yang telah diberikan kepada pasien".

C. Pengertian Rekam Kesehatan Elektronik (RKE)

Electronic Medical Record (EMR) atau Rekam Medis Elektronik (RME) menurut hatta et al. (2013:432) adalah: "Bentuk komputerisasi berbasis rekam kesehatan. Dalam hal ini informasi disimpan dalam seluruh file dan bukan pada setiap elemen data individu".

\section{Kelebihan RKE}

a. Memungkinkan akses informasi secara cepat dan mudah.

b. Memungkinkan adanya copy cadangan (duplikat) informasi yang dapat diambil bila yang asli hilang atau rusak.

c. Memproses transaksi dalam jumlah besar dan sulit secara cepat.

d. Memungkinkan siap mengakses secara cepat untuk beragam sumber profesional.

e. Memungkinkan mengakses secara lebih canggih dan dapat melihat rancangan yang sesuai dengan kehendak (customization).

\section{Kekurangan RKE}

a. Kurangnya definisi yang jelas.

b. Sulit memenuhi kebutuhan pengguna yang beragam.

c. Kurangnya standarisasi.

d. Adanya potensi ancaman terhadap privasi dan sekuritas.

e. Biaya

D. Pengertian Sistem Pencatatan dan Pelaporan Terpadu Puskesmas (SP2PT)

Menurut Yusran (Barsasella, 2012:66): "Sistem Pencatatan dan Pelaporan Terpadu Puskesmas (SP2PT) adalah kegiatan pencatatan dan pelaporan secara menyeluruh (terpadu) dengan konsep wilayah kerja puskesmas".

E. Pengertian 20 Besar Penyakit 
Menurut Departemen Pendidikan Nasional (2008:1343): "Penyakit adalah Gangguan kesehatan yang disebabkan oleh bakteri, virus, atau kelainan sistem (pada makhluk hidup)".

Formulir daftar 10 besar penyakit rawat jalan menurut Direktorat Jenderal Bina Upaya Kesehatan (2011:41): "Formulir untuk data 10 besar penyakit rawat jalan rekapitulasi dari jumlah banyaknya kasus baru pada unit rawat jalan pada satu tahun". Dengan demikian dapat disimpulkan 20 besar penyakit rujukan adalah rekapitulasi rujukan penyakit paling banyak dari data kesakitan yang mencakup data di wilayah pelayanan kesehatan untuk periode tertentu.

\section{F. Pengertian Rujukan}

Menurut Azwar (2010:49), sistem rujukan adalah suatu sistem penyelenggaraan pelayanan kesehatan yang melaksanakan pelimpahan tanggung jawab timbal balik terhadap satu kasus penyakit atau masalah kesehatan secara vertikal dalam arti dari unit yang berkemampuan kurang kepada unit yang lebih mampu atau secara horizontal dalam arti antar unit-unit yang setingkat kemampuannya.

\section{G. Pengertian Perancangan}

Perancangan menurut Ladjamudin (2005:39): "kegiatan yang bertujuan untuk mendesign sistem baru yang dapat menyelesaikan masalah-masalah yang di hadapi perusahaan yang di peroleh dari pemilihan alternatif sistem terbaik ".

\section{H. Pengertian Sistem}

Menurut Tata Sutabri (2012:6) "Sistem adalah sekelompok unsur yang erat hubungannya satu dengan yang lain, yang berfungsi bersama-sama untuk mencapai tujuan tertentu".

\section{Pengertian Informasi}

Menurut Andri Kristanto (2008:5) informasi merupakan "kumpulan data yang diolah menjadi bentuk yang lebih berguna dan lebih berarti bagi yang menerima".

\section{METODE PENELITIAN}

Pada penelitian ini penulis melakukan penelitian dengan metode penelitian kualitatif dengan pendekatan deskriptif.

1. Menurut Suryono (2010:01) "Metode Peneliatian Kualitatif adalah metode penyelidikan untuk mencari jawaban atas suatu pertanyaan, dilakukan secara sistematik menggunakan seperangkat prosedur untuk menjawab pertanyaan, mengumpulkan fakta, menghasilkan suatu temuan yang tidak bisa ditetapkan sebelumnya dan menghasilkan suatu temuan yang dapat dipakai melebihi batasan-batasan penelitian dari suatu pandangan perspektif populasi penelitian yang terlibat".

2. Menurut Sugiyono (2014 : 22) metode penelitian deskriptif adalah metode yang digunakan untuk menggambarkan atau menganalisis suatu hasil penelitian tetapi tidak digunakan untuk membuat kesimpulan yang lebih luas.

\section{Teknik Pengumpulan Data}

Teknik pengumpulan data yang digunakan oleh penulis dalam penulisan skripsi ini adalah :

a. Wawancara

Wawancara adalah proses memperoleh penjelasan untuk mengumpulkan informasi dengan menggunakan cara tanya jawab bisa sambil bertatapan muka ataupun tanpa tatap muka yaitu melalui media telekomunikasi antara pewawancara dengan orang yang diwawancarai, dengan atau tanpa menggunakan pedoman. Dalam hal ini penulis mengumpulkan data dengan cara wawancara langsung dengan pihak-pihak yang berwenang yang mengenai masalah tentang pelaporan 20 besar penyakit rujukan yang ada di UPT Puskesmas Babakan Sari Kota Bandung.

b. Observasi 
Observasi adalah suatu kegiatan mendapatkan informasi yang diperlukan untuk menyajikan gambaran riil suatu peristiwa atau kejadian. Penulis melakukan penelitian dengan melakukan pengamatan secara langsung terhadap objek penelitian dengan melakukan analisis kualitatif terhadap pelaporan 20 besar penyakit rujukan di UPT Puskesmas Babakan Sari Kota Bandung

c. Studi Pustaka

Studi Pustaka adalah proses memperoleh informasi melalui buku referensi dengan mempelajari teori-teori yang berkaitan dengan judul yang penulis ambil. Selain itu, menggunakan internet sebagai landasan untuk memecahkan masalah.

Sedangkan untuk metodelogi pengembangan perangkat lunak, penulis menggunakan metode waterfall. Waterfall sering juga disebut model sekuensial linier (sequential linear) atau alur hidup klasik (classic life cycle) adalah suatu proses pengembangan perangkat secara sekuensial atau pengembangan perangkat lunak berurutan yang dimulai dari analisis, desain, pengkodean, pengujian dan tahap pendukung .

\section{HASIL DAN PEMBAHASAN}

1. Permasalahan yang Dihadapi

Berdasarkan hasil penelitian yang dilakukan, terdapat beberapa masalah pada sistem informasi 20 besar penyakit rujukan di UPT Puskesmas Babakan Sari Kota bandung yaitu sebagai berikut:

a. Rekapitulasi jumlah penyakit untuk laporan 20 besar penyakit berdasarkan rujukan masih dilakukan secara manual

b. Belum adanya sistem komputerisasi pelaporan 20 besar penyakit rujukan

c. Sistem yang digunakan masih kurang efektif mengakibatkan pembuatan laporan 20 besar penyakit rujukan cukup memakan waktu yang lama

d. Terlambatnya pelaporan karena masih dilakukan secara manual dengan menghitung satu persatu kemudian mengelompokkan jumlah penyakit rujukan terbanyak

\section{Upaya Pemecahan Masalah}

a. Petugas melakukan perekapan data pelayanan rujukan diluar jam kerja sehingga tidak mengganggu pekerjaan yang lain

b. Dalam pembuatan laporan 20 besar penyakit rujukan, petugas mengaplikasikan sistem yang terkomputerisasi yaitu dengan menggunakan microsoft excel

c. Perekapan data yang dihitung dari buku register rujukan dilakukan seminggu sekali, hal ini agar perhitungan jumlah penyakit rujukan terbanyak berdasarkan diagnosa pasien lebih akurat

\section{Perancangan Sistem Informasi}

Untuk alat bantu perancangan system, penulis menggunakan DFD (Data Flow Diagram) sebagai alat bantu penggambaran perancangan. Microsoft Access 2007 sebagai Database atau penyimpanan data dan Blackbox sebagai pengujian sistem. Sistem informasi 20 besar penyakit rujukan yang dirancang ini menggunakan Data Flow Diagram. Perancangan sistem yang digunakan, yaitu Microsoft Visual Studio 2010, dengan database Microsoft Access 2007. 
1. Flowmap Sistem yang Dirancang

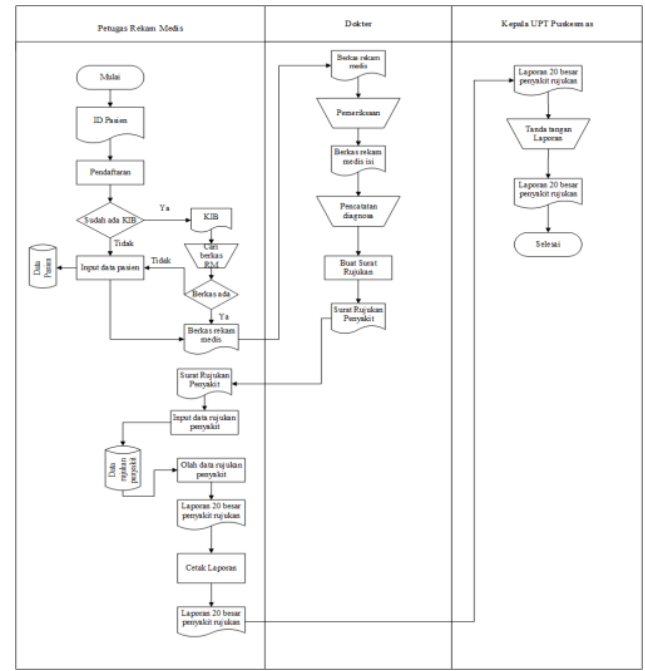

Gambar 1 Rancangan Flowmap sistem yang Dirancang

Sumber : Diolah oleh Penulis (2018)

\section{Rancangan Diagram Konteks Sistem}

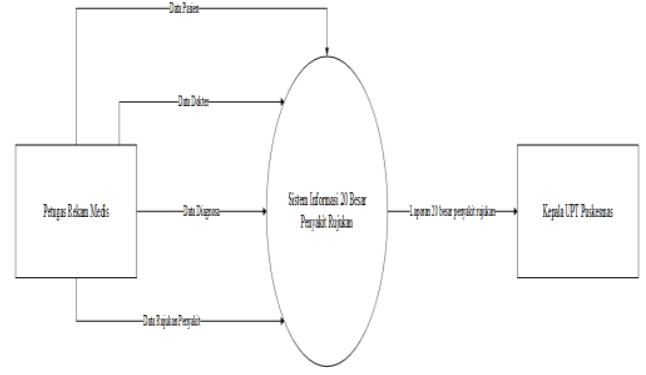

Gambar 2 Rancangan Diagram Konteks Sistem

Sumber : Diolah Oleh Penulis (2018)

\section{Rancangan DFD Level 0 Sistem}

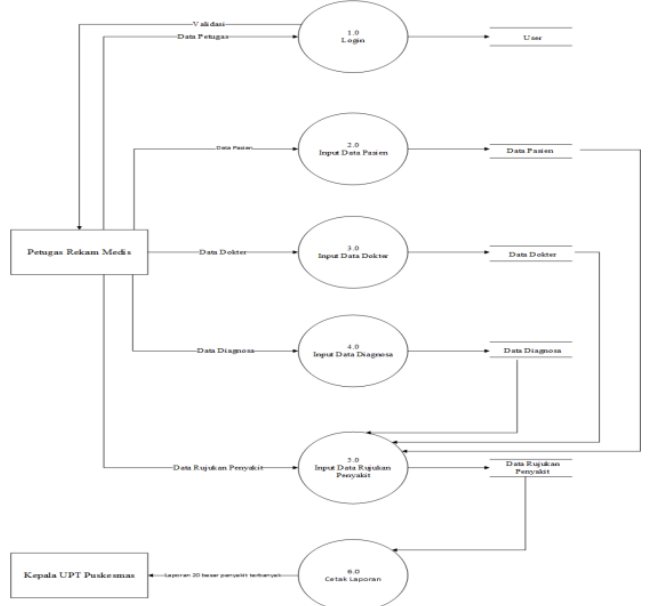

Gambar 3 Rancangan DFD Level 0 Sistem

Sumber : Diolah Oleh Penulis (2018)

4. Rancangan DFD Level 1 proses 1.0

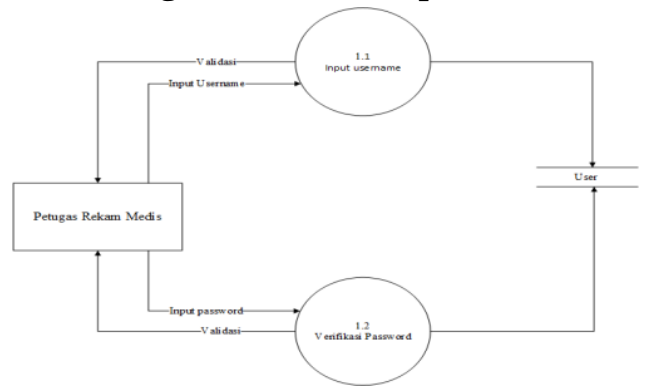

Gambar 4 Rancangan DFD Level 1 proses 1.0

Sumber : Diolah Oleh Penulis (2018)

5. Rancangan DFD Level 1 proses 2.0

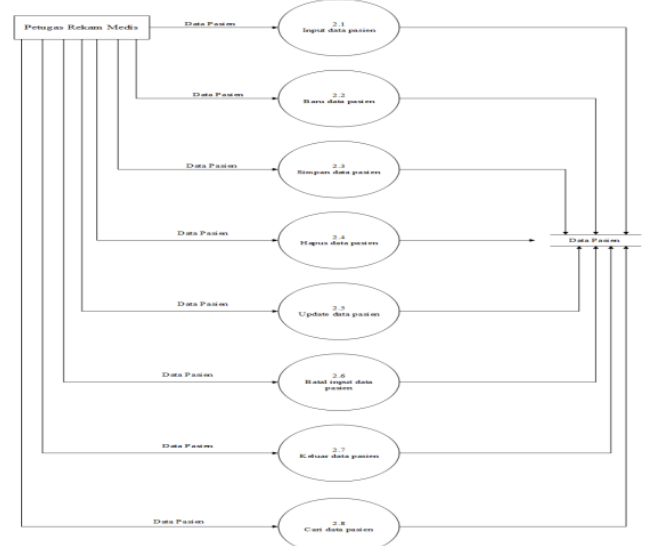

Gambar 5 Rancangan DFD Level 1 proses 2.0 
Sumber : Diolah Oleh Penulis (2018)

6. Rancangan DFD Level 1 proses 3.0

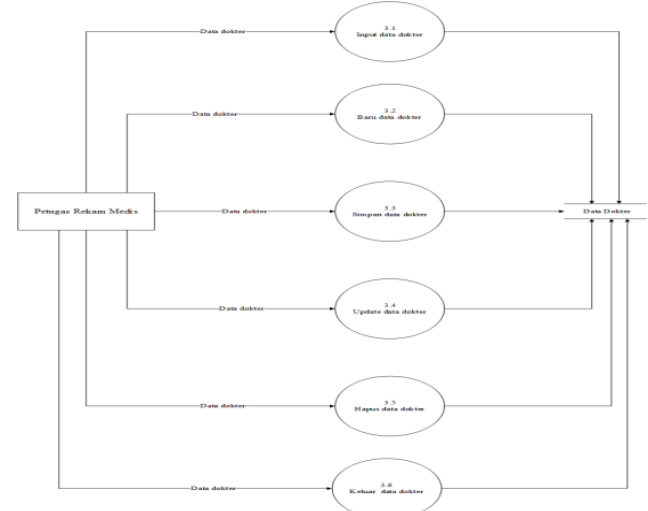

Gambar 6 Rancangan DFD Level 1 proses 3.0

Sumber : Diolah Oleh Penulis (2018)

7. Rancangan DFD Level 1 proses 4.0

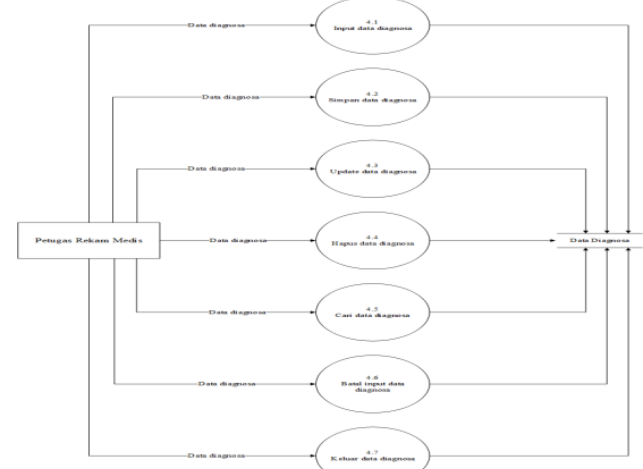

Gambar 7 Rancangan DFD Level 1 proses 4.0

Sumber : Diolah Oleh Penulis (2018)

8. Rancangan DFD Level 1 proses 5.0

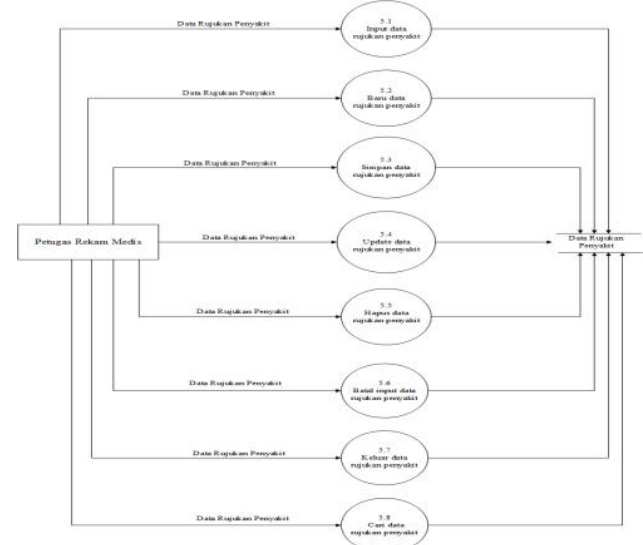

Gambar 8 Rancangan DFD Level 1 proses 5.0
Sumber : Diolah Oleh Penulis (2018) 9. Rancangan DFD Level 1 proses 6.0

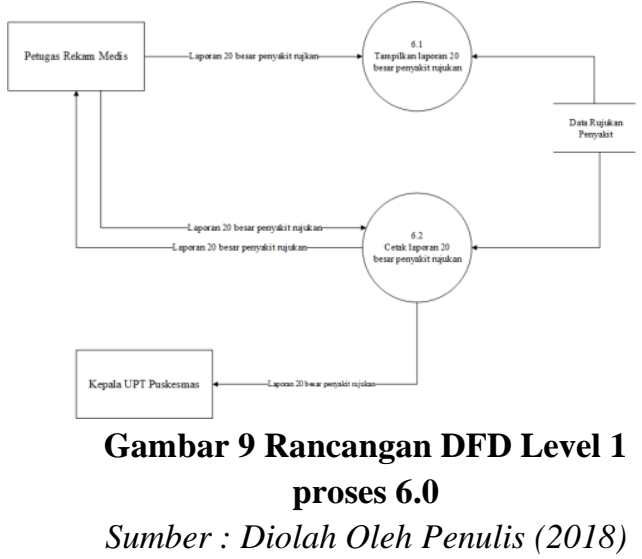

10. Entity Relationship Diagram (ERD)

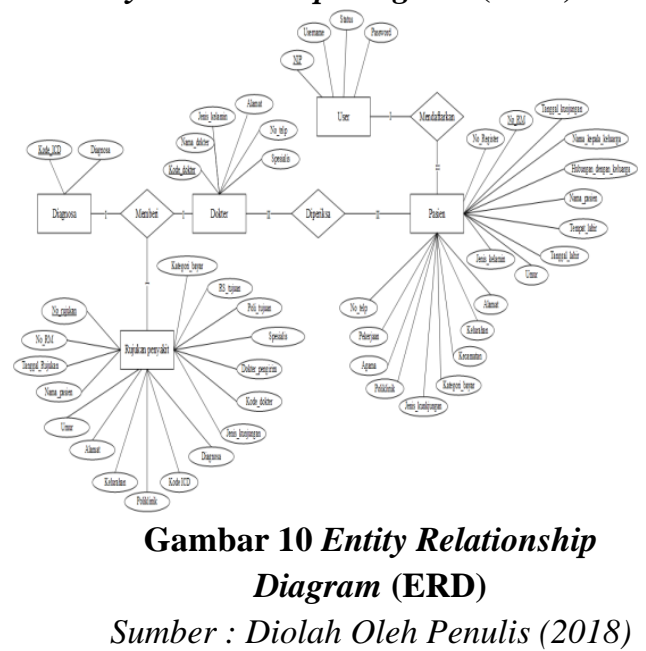

11. Skema Relasi Tabel

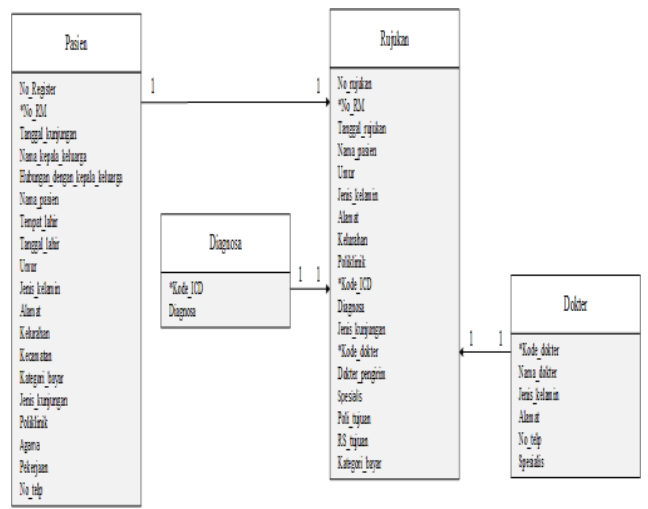

Gambar 11 Skema Relasi Tabel Sumber : Diolah Oleh Penulis (2018) 


\section{Rancangan Masukan}

Rancangan masukan dalam perancangan sistem informasi ini diawali dengan menampilkan form log in user, yaitu langkah awal user untuk mengakses dan melakukan input data rujukan pasien ke dalam sistem yang nantinya akan diolah dan menghasilkan keluaran laporan.

\section{Rancangan Keluaran}

Rancangan keluaran berisi gambaran tentang keluaran yang dihasilkan oleh sistem yang dirancang. Dalam hal ini penulis merancang sistem informasi 20 besar penyakit rujukan di UPT Puskesmas Babakan Sari Bandung. Keluaran yang dihasilkan oleh rancangan sistem informasi yang penulis buat adalah laporan di media kertas (print out) yang berasal dari olahan database.

\section{Implementasi}

Tahap implementasi sistem merupakan tahap menerjemahkan perancangan berdasarkan hasil analisis dalam bahasa yang dapat dimengerti oleh mesin serta penerapan perangkat lunak pada keadaan yang sesungguhnya.

\section{Form Menu Utama}

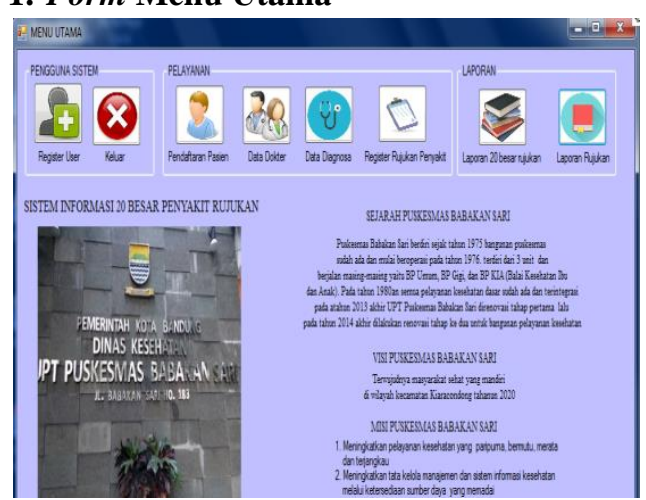

Gambar 12 Tampilan Menu Utama Sumber : Diolah Oleh Penulis (2018)

\section{Form Login}

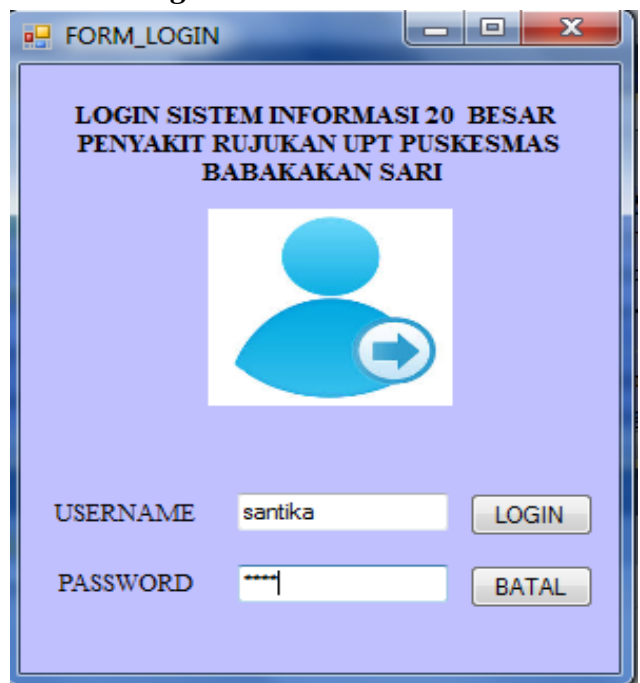

Gambar 13 Tampilan Form Login

Sumber : Diolah Oleh Penulis (2018)

\section{Form Register User}

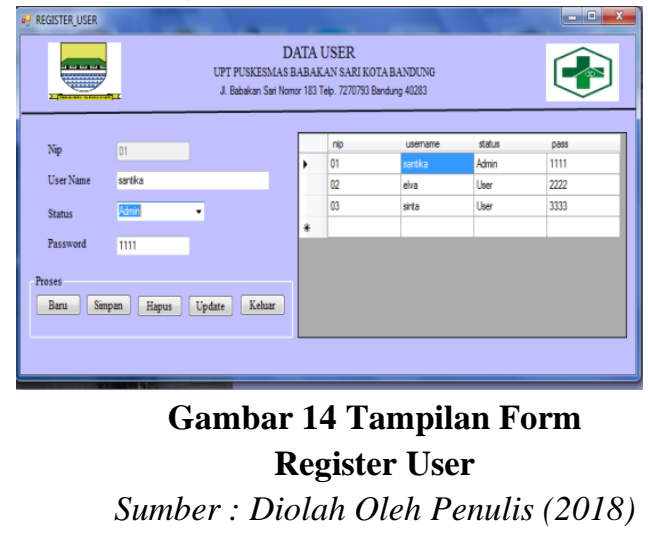

\section{Form Data Dokter}

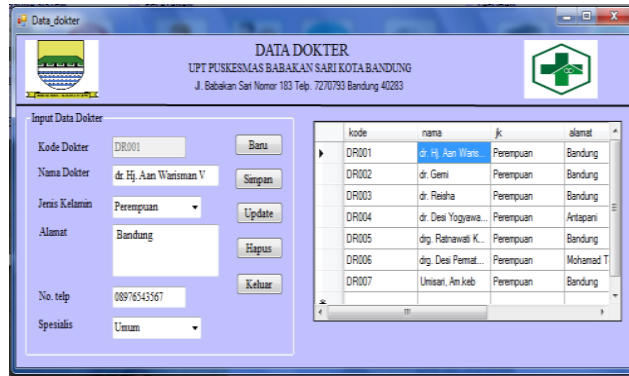

Gambar 15 Tampilan Form Data

Dokter

Sumber : Diolah Oleh Penulis (2018) 


\section{Form Data Diagnosa}

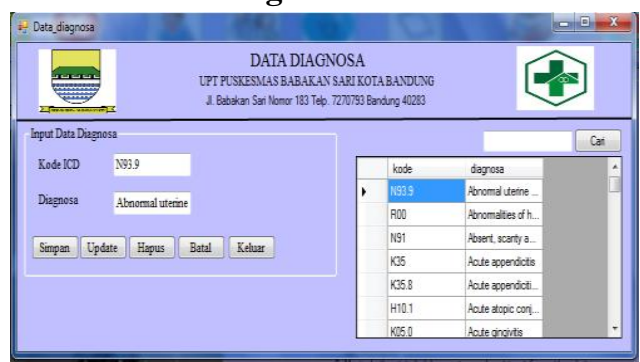

Gambar 16 Tampilan Form Data Diagnosa

Sumber : Diolah Oleh Penulis (2018)

\section{Form Register Pasien}

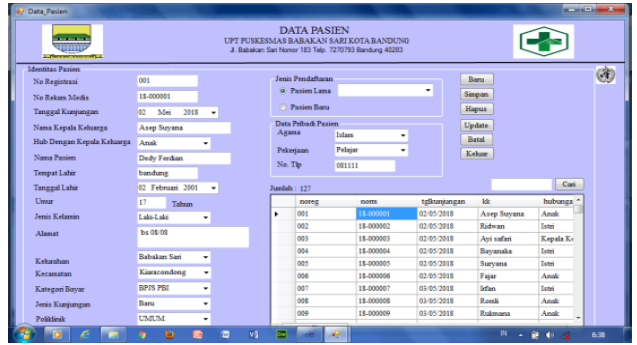

Gambar 17 Tampilan Form Register Pasien

Sumber : Diolah Oleh Penulis (2018)

\section{Form Register Rujukan}

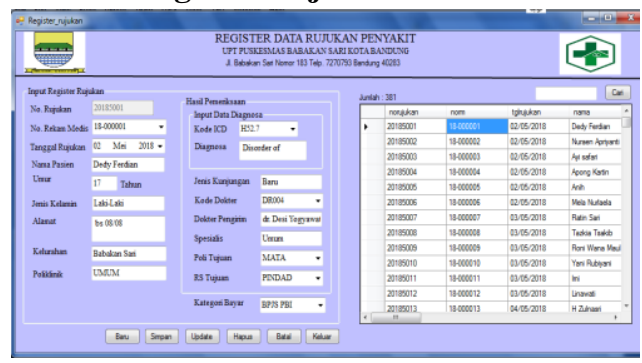

Gambar 18 Tampilan Form

Register Rujukan

Sumber : Diolah Oleh Penulis (2018)

8. Form Cetak Laporan 20 Besar Penyakit Rujukan

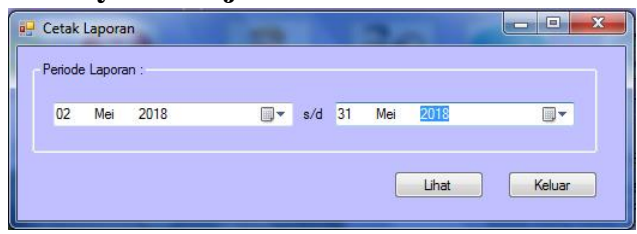

Gambar 19 Tampilan Form Cetak Laporan 20 besar rujukan
Sumber : Diolah Oleh Penulis (2018)

9. Form Cetak Laporan Berdasarkan Filter

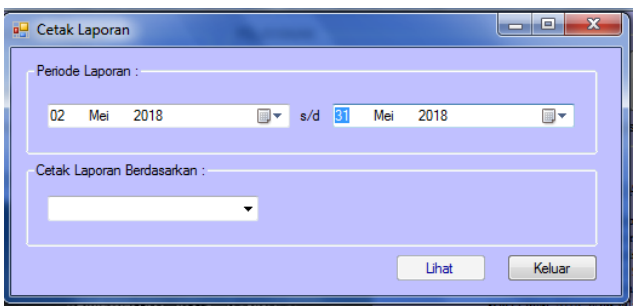

Gambar 20 Tampilan Form Cetak Laporan Berdasarkan Filter

Sumber: Diolah Oleh Penulis (2018)

10. Tampilan Laporan 20 Besar Penyakit Rujukan

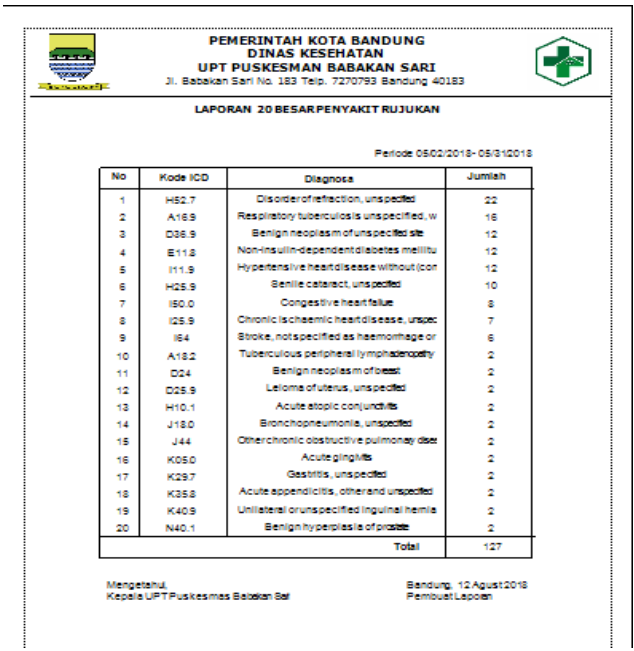

Gambar 21 Tampilan Laporan 20 besar penyakit

Sumber : Diolah Oleh Penulis (2018)

11. Tampilan Laporan Rujukan Per Periode
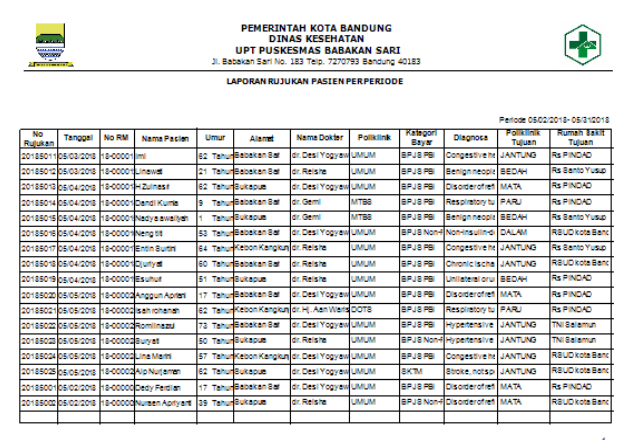

Gambar 22 Tampilan Laporan Rujukan Per Periode 
Sumber : Diolah Oleh Penulis (2018)

12. Tampilan Laporan Rujukan Per Wilayah

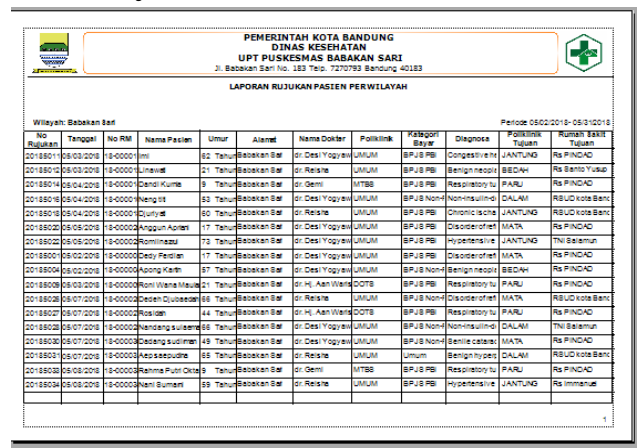

Gambar 23 Tampilan Laporan

Rujukan Per Wilayah

Sumber : Diolah Oleh Penulis (2018)

\section{Tampilan Laporan Rujukan Per} Dokter

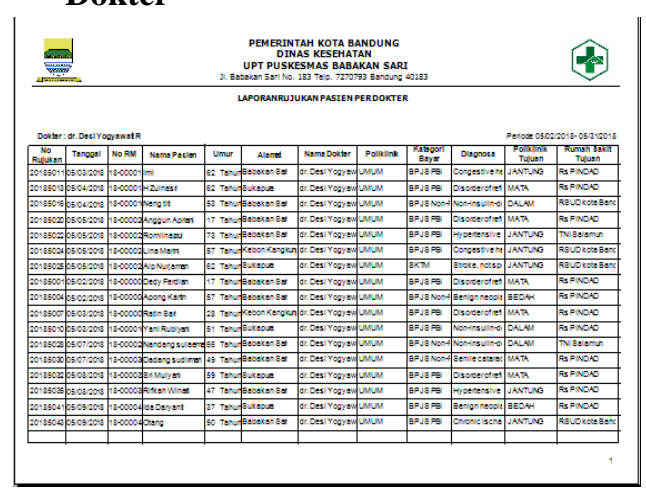

Gambar 24 Tampilan Laporan Rujukan Per Dokter

Sumber : Diolah Oleh Penulis (2018)

\section{Tampilan Tampilan Laporan} Rujukan Per Jenis Kunjungan
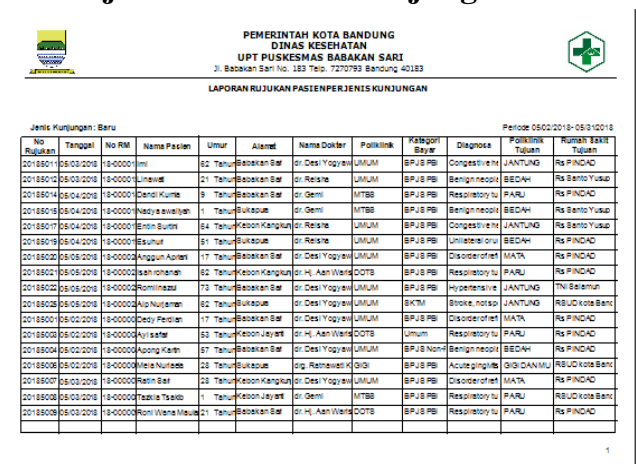

Gambar 25 Tampilan Laporan Rujukan Per Jenis Kunjungan Sumber : Diolah Oleh Penulis (2018)
15. Tampilan Laporan Per Poliklinik Tujuan

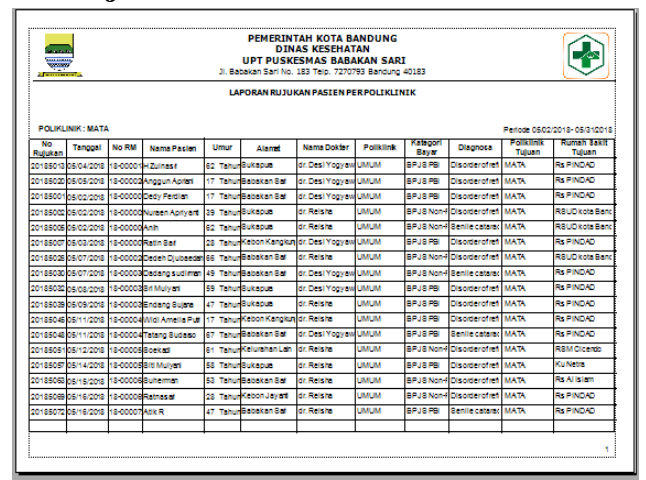

Gambar 26 Tampilan Laporan Per Poliklinik Tujuan

Sumber : Diolah Oleh Penulis (2018)

16. Tampilan Laporan Per Poliklinik Tujuan

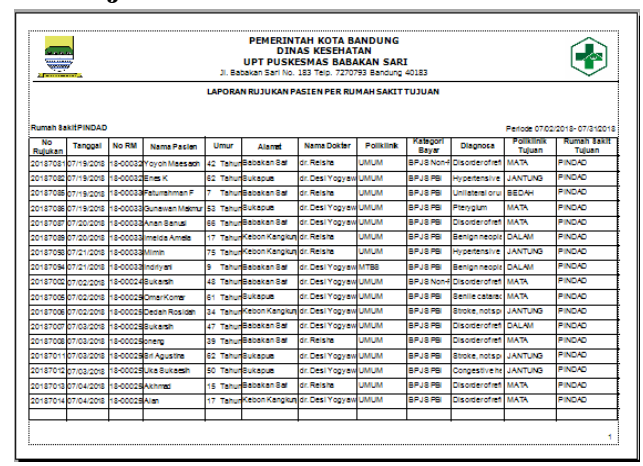

Gambar 27 Tampilan Laporan Per Rumah Sakit

Sumber : Diolah Oleh Penulis (2018)

17. Tampilan Laporan Per Jenis Kelamin

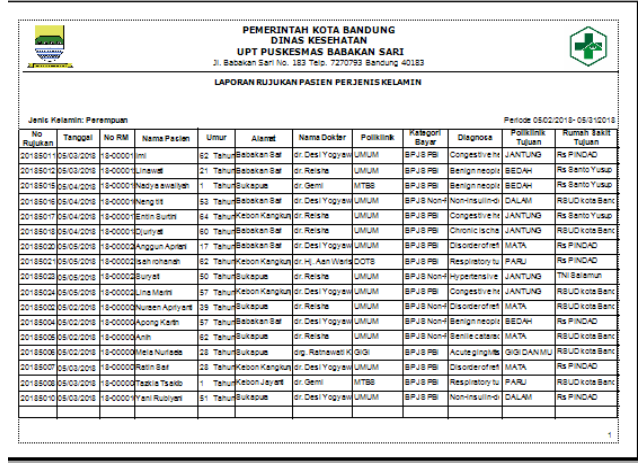

Gambar 28 Tampilan Laporan Per Jenis Kelamin

Sumber : Diolah Oleh Penulis (2018) 
18. Tampilan Laporan Per Kategori Bayar

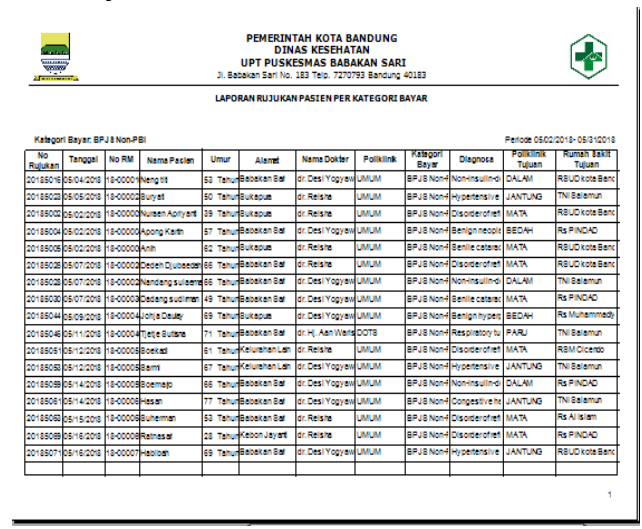

Gambar 29 Tampilan Laporan Per Kategori Bayar

Sumber : Diolah Oleh Penulis (2018)

\section{Tampilan Laporan Indeks Penyakit}

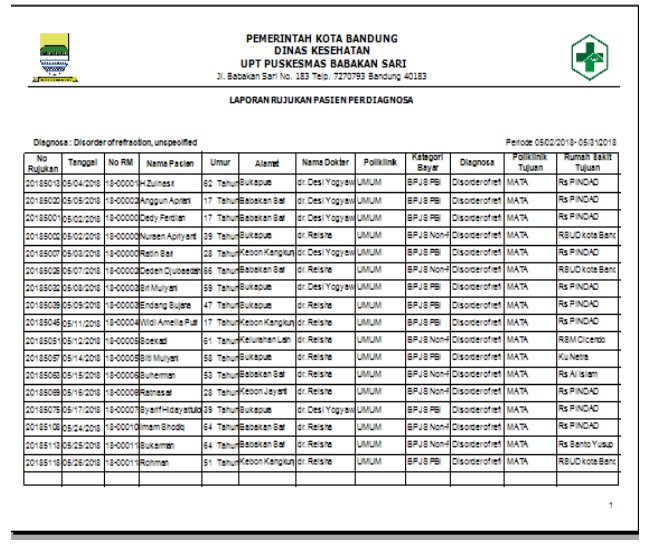

Gambar 30 Tampilan Laporan Indeks Penyakit

Sumber : Diolah Oleh Penulis (2018)

\section{SPESIFIKASI HARDWARE DAN SOFTWARE \\ 1. Spesifikasi Hardware}

Spesifikasi minimal perangkat keras yang digunakan untuk menggunakan Sistem Informasi 20 besar penyakit rujukan adalah sebagai berikut :
a. Processor : Intel (R) Atom
(TM) CPU N2600@1.60GHz
b. Memory (RAM) : $2.00 \mathrm{~GB}$
c. Harddisk : $8 \mathrm{~GB}$
d. Lain-lain : Keyboard, Mouse,
Printer

\section{Spesifikasi Software}

a. Sistem Operasi : Windows 7

b. Bahasa Pemograman :Microsoft Visual Studio 2010

c. Pengolahan Database:Microsoft Access 2007

d. Pengolahan data :Microsoft Office Word

e. Pengolahan Laporan : Crystal Report

f. Rancangan Diagram : Microsoft Visio 2013

\section{KESIMPULAN}

Berdasarkan Penelitian yang telah dilakukan, maka penulis dapat mengambil kesimpulan sebagai berikut :

a. Pelaksanaan sistem informasi informasi 20 besar penyakit rujukan di UPT Puskesmas Babakan Sari Kota Bandung masih belum optimal.

b. Permasalahan dalam sistem informasi 20 besar penyakit rujukan di UPT Puskesmas Babakan Sari Kota Bandung yaitu:

1) Rekapitulasi jumlah penyakit untuk laporan 20 besar penyakit berdasarkan rujukan masih dilakukan secara manual.

2) Belum adanya sistem komputerisasi pelaporan 20 besar penyakit rujukan.

3) Pelaporan 20 besar penyakit rujukan dibuat menggunakan microsoft excel sehingga penginputan datanya membutuhkan waktu yang lama.

4) Upaya yang dilakukan oleh pihak puskesmas yaitu dengan melakukan kegiatan rekapitulasi data 20 besar penyakit rujukan diluar jam kerja agar petugas bisa lebih teliti dalam merekap 20 besar penyakit rujukan terbanyak.

5) Perancangan sistem informasi 20 besar penyakit rujukan ini menggunakan aplikasi Microsoft Visual Studio 2010 dengan 
menggunakan database Microsoft Access 2007.

\section{Saran}

Dari kesimpulan diatas, penulis memberikan saran sebagai masukan yang tujuannya untuk meningkatkan sistem informasi 20 besar penyakit rujukan di UPT Puskesmas Babakan Sari Kota Bandung, yaitu :

a. Perlu adanya penambahan tenaga kesehatan dalam pengolahan laporan 20 besar penyakit rujukan agar dapat menghasilkan laporan yang tepat dan akurat.

b. Dibuatkannya perancangan sistem informasi 20 besar penyakit rujukan yang dapat mempercepat pembuatan laporan 20 besar penyakit rujukan di UPT Puskesmas Babakan Sari Kota Bandung.

c. Perlu adanya pemeliharaan dan perawatan terhadap sistem informasi yang telah dirancang dan juga terhadap perangkat komputer yang digunakan karena untuk menjaga kualitas dari sistem informasi yang dirancang.

d. Memberikan pelatihan untuk para petugas yang akan menggunakan sistem informasi 20 besar penyakit rujukan di UPT Puskesmas Babakan Sari Kota Bandung.

\section{DAFTAR PUSTAKA}

[1] Al-Bahar. Bin Ladjamudi (2005), Analisis dan Desain Sistem Informasi, Graha Ilmu, Tangerang.

[2] Al-Bahra. Bin Ladjamudin (2006), Rekayasa Perangkat Lunak, Graha Ilmu, Tanggerang.

[3] Azwar, Azrul (2010), Pengantar Administrasi Kesehatan Edisi Ketiga, Binarupa Aksara, Jakarta.

[4] Barsasella, Diana (2012), Sistem Informasi Kesehatan, Mitra Wacana Medika, Jakarta.
[5] Darmawan, Deni, dan Nur Fauzi, Kunkun (2015), Sistem Informasi Manajemen, PT Remaja Rosda Karya, Bandung.

[6] Darmayuda, Ketut (2014), Aplikasi Basis Data dengan Visual Basic.NET, Informastika, Bandung.

[7] Direktorat Jenderal Bina Pelayanan Medik (2006), Pedoman Penyelenggaraan dan Prosedur Rekam Medis Rumah Sakit di Indonesia, Jakarta

[8] Effendy, Nasrul (2012), Dasar Dasar Keperawatan Kesehatan Masyarakat, EGC, Jakarta.

[9] Hatta, Gemala R (2013), Pedoman Manajemen Informasi Kesehatan di Sarana Pelayanan Kesehatan, Universitas Indonesia, Jakarta.

[10] Husda, Nur Elfi, dan Wangdra,Yvonne (2016), Pengantar Teknologi Informasi, Baduose Media, Jakarta.

[11] Jogiyanto (2005), Analisis dan Desain Sistem Informasi, Andi, Yogyakarta.

[12] Keputusan Menteri Kesehatan Republik Indonesia No. 128/MENKES/SK/II/2004 tentang Kebijakan Dasar Puskesmas

[13] Kristanto, Andri (2008), Perancangan Sistem Informasi dan Aplikasinya, Gava Media, Yogyakarta.

[14] Lubis, Adyanata (2016), Basis Data Dasar Untuk Mahasiswa Ilmu Komputer, Yogyakarta.

[15] Peraturan Menteri Kesehatan No. 7 5 tahun 2014 tentang Puskesmas

[16] Peraturan Menteri Kesehatan No. 269/MENKES/PER/III/2008 tentang Rekam Medis

[17] Rosa, M Shalahuddin (2013), Rekayasa Perangkat Lunak, Informatika, Bandung.

[18] SK Menteri Kesehatan RI No. 001 tahun 2012, Pengertian Surat Rujukan

[19] Sugiyono (2014), Metodologi Penelitian Pendidikan Kuantitatif, Kualitatif dan R\&D, Alfabeta, Bandung. 
[20] Suhadi dan Muh. Kardi Rais (2015), Perencanaan Puskesmas, TIM, Jakarta.

[21] Sujarweni,V. Wiratna (2014), Metodologi Penelitian, Pustaka Baru, Yogyakarta.

[22] Suryono (2010), Metodologi Penelitian Kualitatif dalam Bidang Kesehatan, Nuha Medika, Yogyakarta.

[23] Sutabri, Tata (2012), Analisis Sistem Informasi, Andi, Yogyakarta.

[24] Sutanta, Edhy (2003), Sistem Informasi Manajemen, Graha, Jakarta.

[25] Suwartika, Rini (2011), Modul Rekayasa Perangkat Lunak, Bandung.

[26] Syarifudin, Hamidah (2012), Kebidanan dan Komunitas, Kedokteran ECG, Jakarta.

[27] Taufani, Dani (2009), Mengolah Data dengan Microsoft Office Access 2007, Bandung. 